\title{
Rapid Quantification of Peptide Oxidation Isomers From Complex Mixtures
}

Niloofar Abolhasani Khaje ${ }^{1}$ and Joshua S. Sharp ${ }^{1,2}$

1. Department of BioMolecular Sciences, School of Pharmacy, University of Mississippi, University, Mississippi 38677

2. Depertmant of Chemistry and Biochemistry, University of Mississippi, University, Mississippi 38677

\section{Supplementary Information}




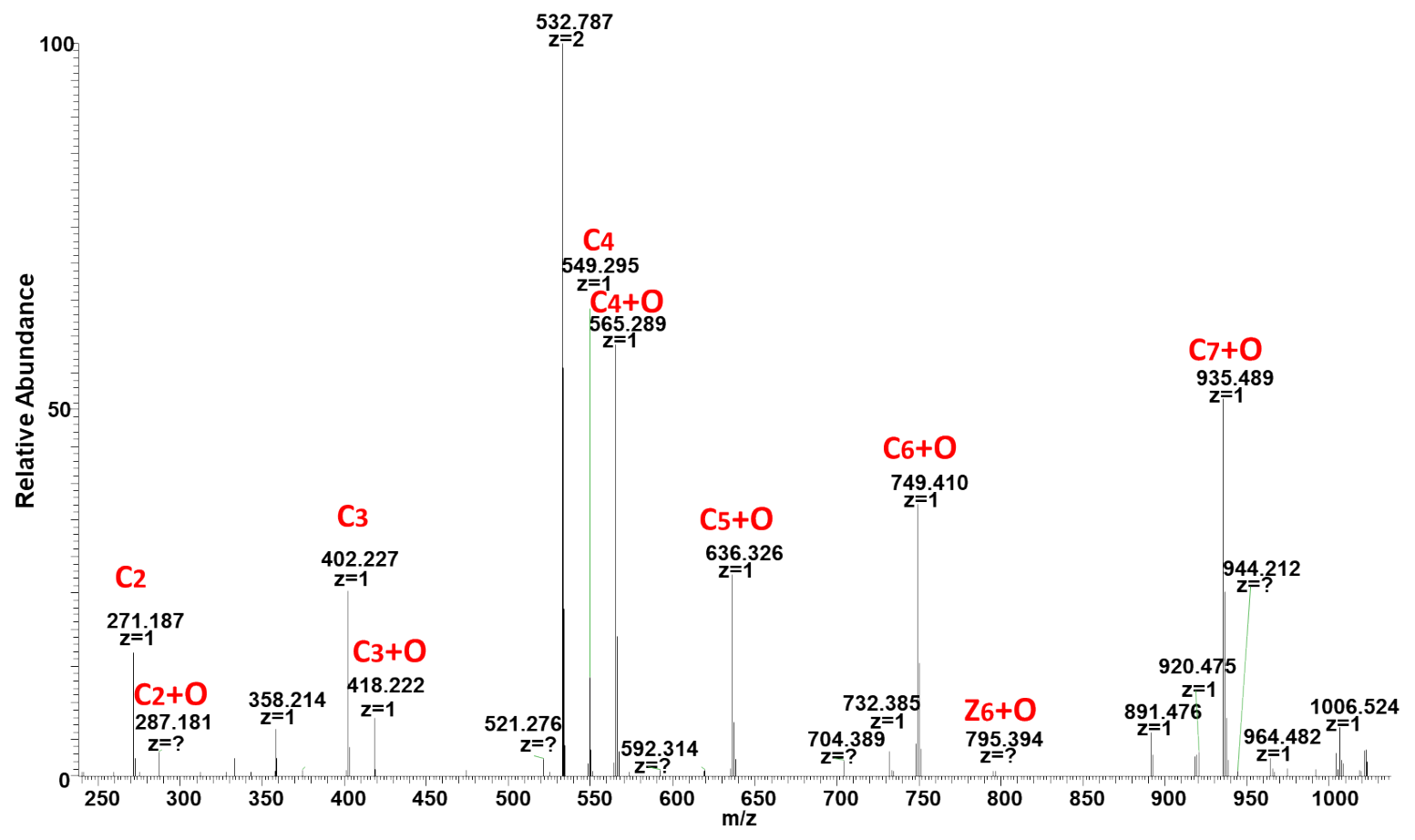

Figure S1. Annotated ETD spectrum the 1:1:1 mixture of synthetic peptide isomers, obtained at maximum LC peak height. 

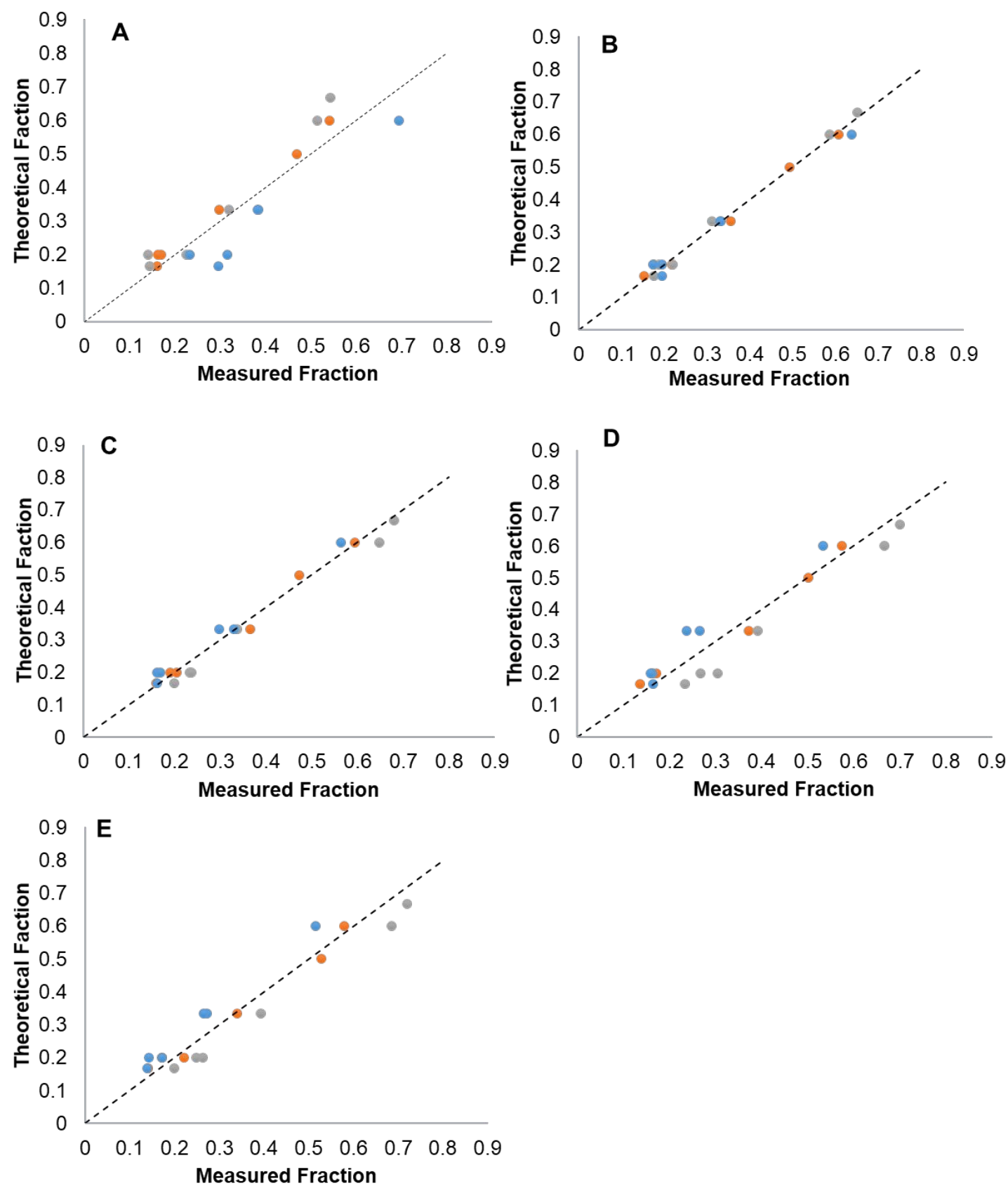

Figure S2. Measured oxidation of RPMFAIWK oxidation isomers at six relative concentrations calculated using ZIC-HILIC ETD spectra. Each figure represents quantification from each particular retention time. A, B, C, D, and E figures represent A1, A2, A3, A4, and A5 retention times as shown in Figure 3A, respectively. Orange, gray, and blue circles represent Hyp2, Tyr4, and Ser5 oxidation, respectively. No systematic error is observed, representing the variation in measurements are due to random error at different retention time sampled by ETD for quantitation. 


\section{A. $\quad 81.05 \%$ sequence coverage}

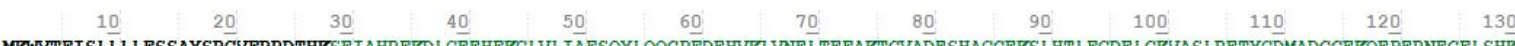
MKWVTFISLLLLFSSAYSRGVFRDTHKSEIAHRFRDGEEHFKGLVLIAFSQYLQQPFFEHVKLVNELTEFAKTCVADESHAGCEKSLHTLFGDELCKVASLRETYGDMADCCERQEPERNECFLSHK

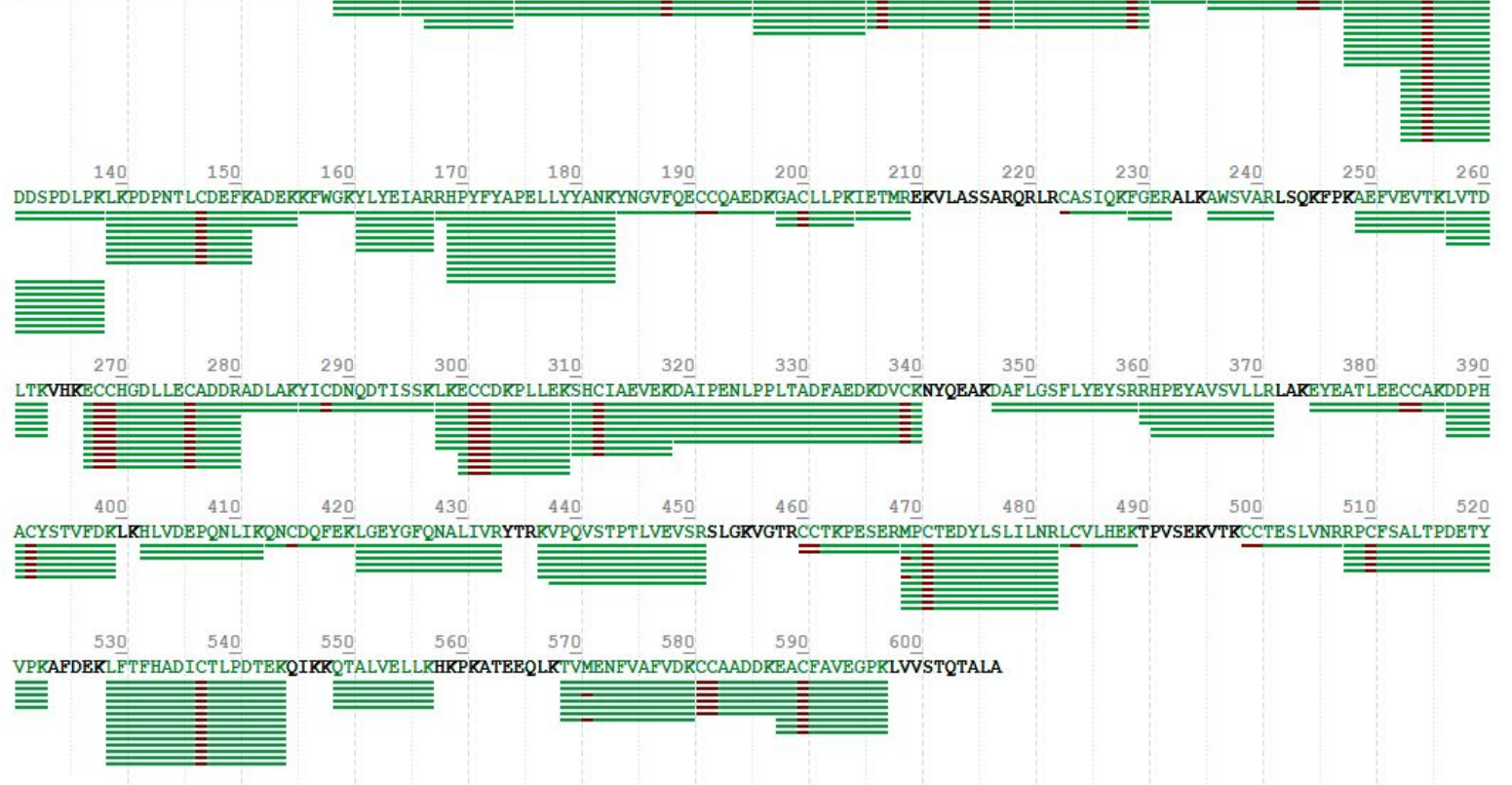

\section{B. $\quad 76.44 \%$ sequence coverage}

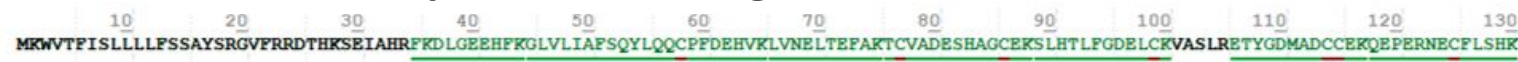

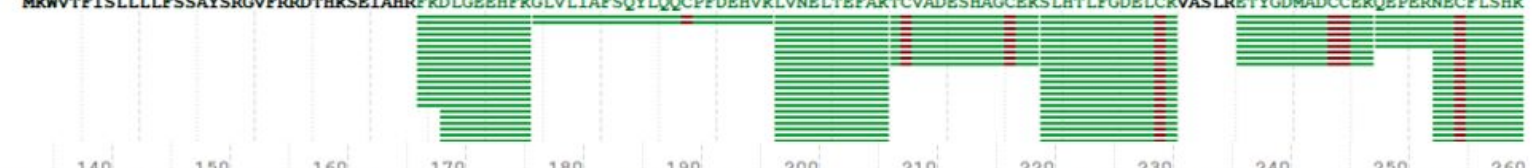

$\begin{array}{llllllllll}140 & 150 & 160 & 170 & 180 & 190 & 200 & 210 & 220 & 230\end{array}$
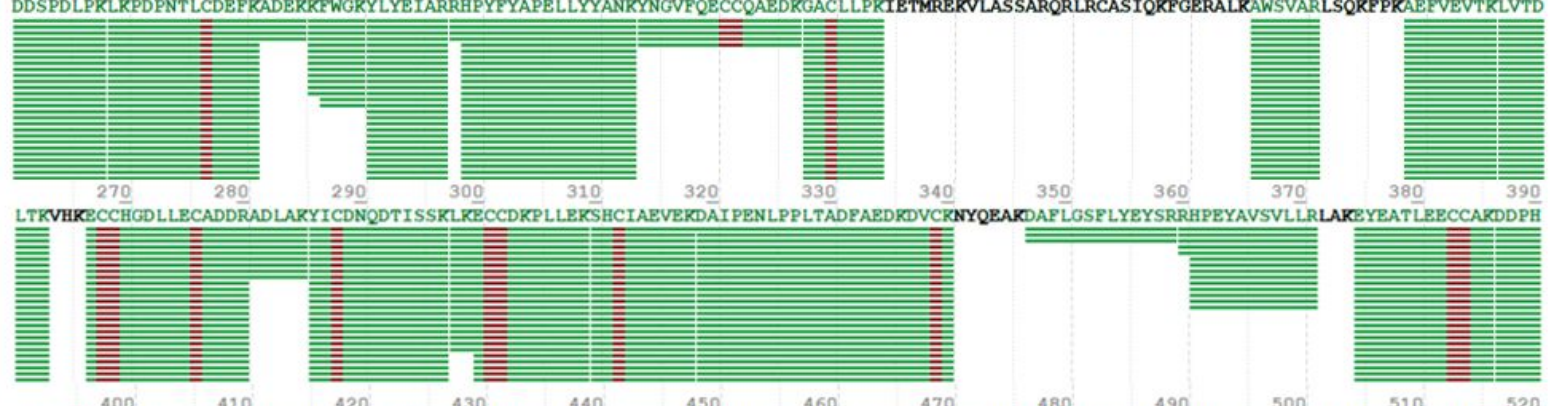

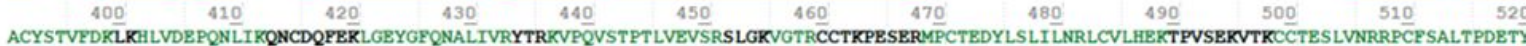

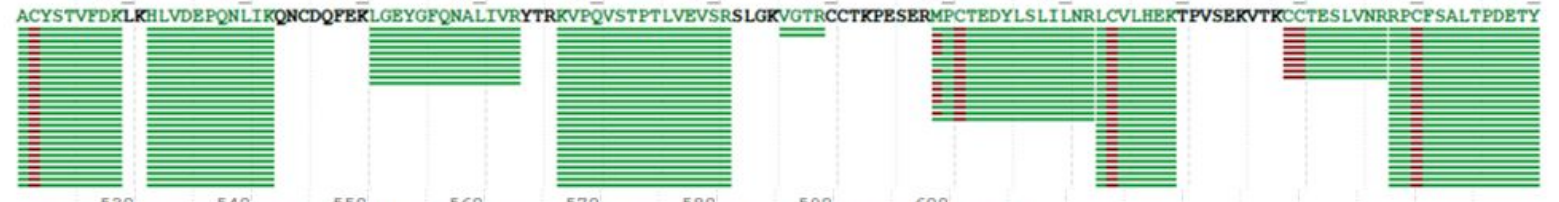

VPKAFDEKL FTFHADICTLPDTEKQIKKQTALVELLRHKPRATEEQLKTVMENFVAFVDKCCAADDKEACFAVEGPKLVVSTQTALA

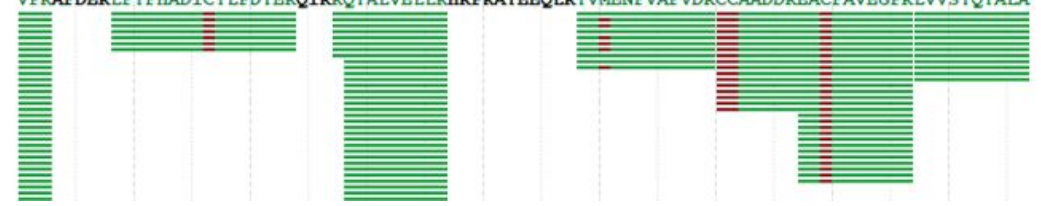

Figure S3. Sequence coverage comparison of BSA between (A) ZIC-HILIC and (B) C18 RPLC. While the repeat count is higher for C18 RPLC, the sequence coverage is higher for ZIC-HILIC. 


\section{A. $\quad 98.70 \%$ sequence coverage}

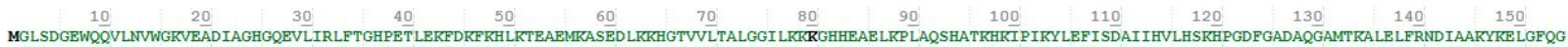

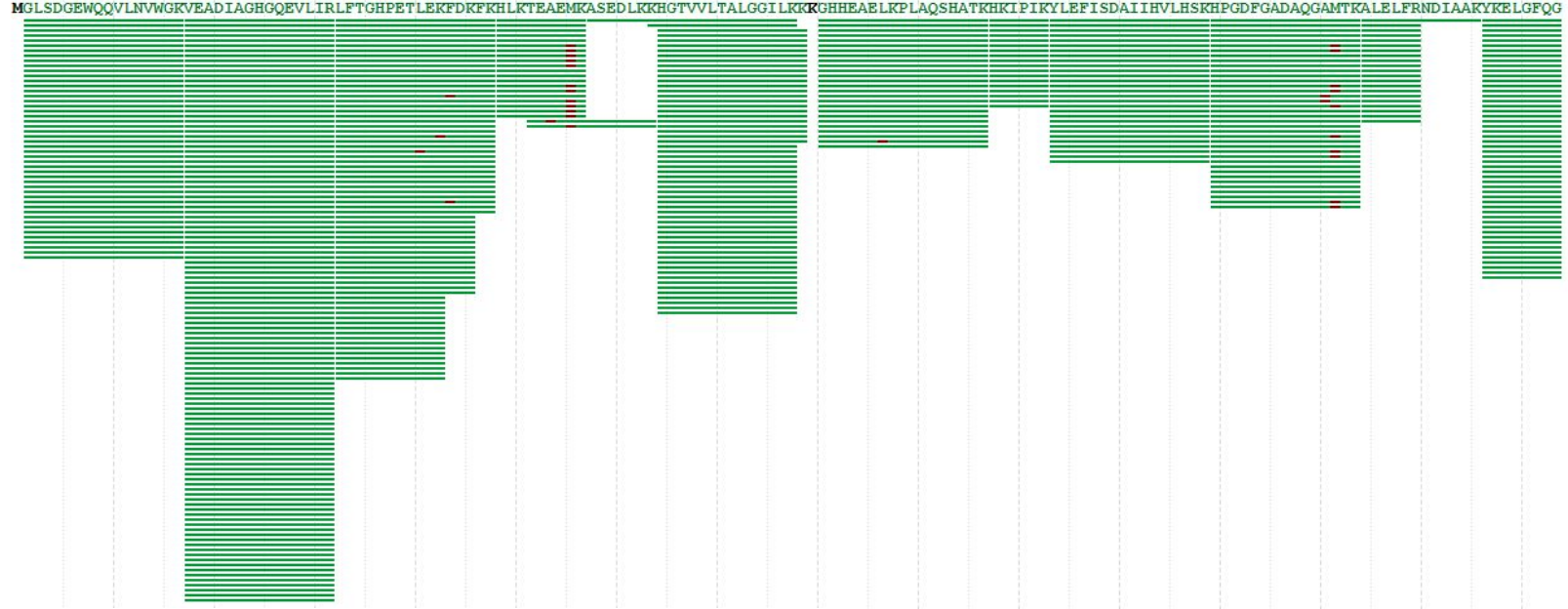

B. $\quad 95.45 \%$ sequence coverage

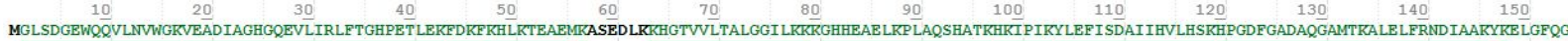

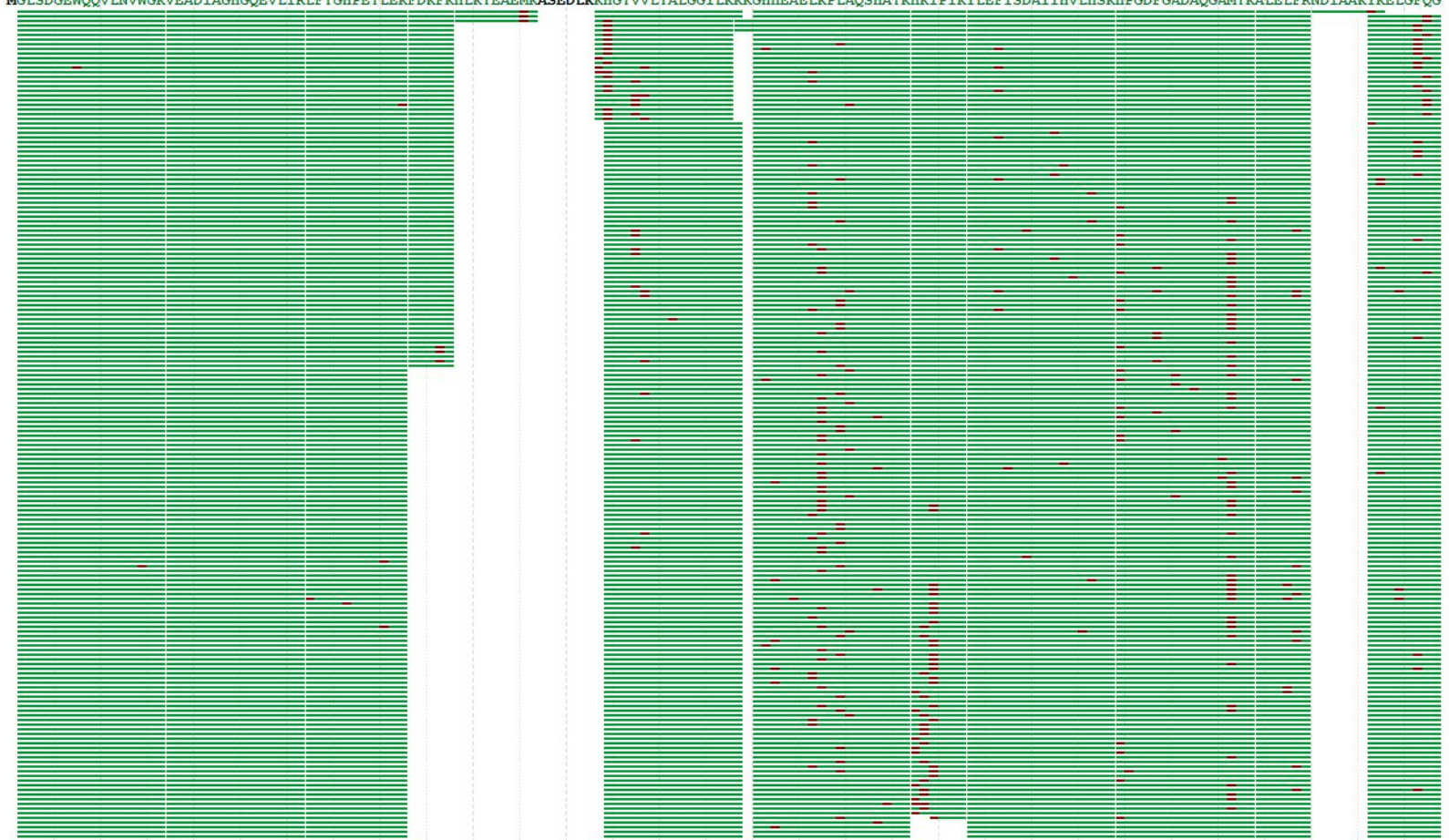

Figure S4. Sequence coverage comparison of oxidized myoglobin between ZIC-HILIC and C18 RP. (A) Myoglobin sequence coverage achieved by ZIC-HILIC. (B) myoglobin sequence coverage using C18 RP. 
A.

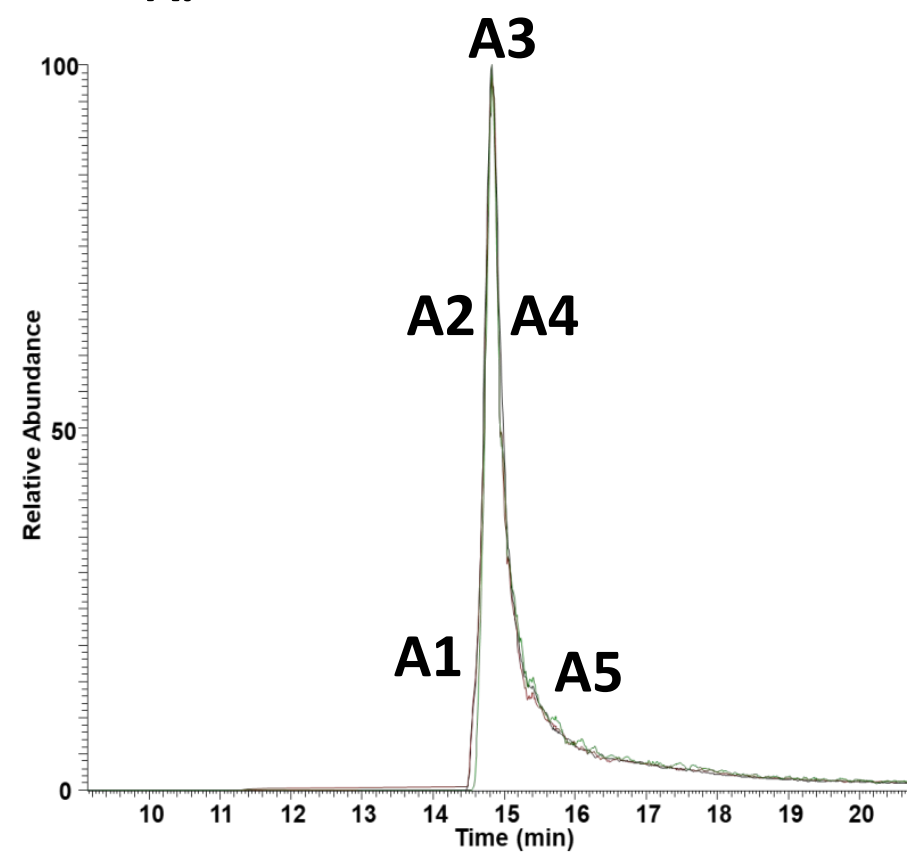

B.

\begin{tabular}{|lccc|}
\hline $\begin{array}{l}\text { Oxidation } \\
\text { Percentage }\end{array}$ & Hyp2 & Y4 & S5 \\
\hline Theoretical & $\mathbf{3 3 . 3 3}$ & $\mathbf{3 3 . 3 3}$ & $\mathbf{3 3 . 3 3}$ \\
\hline A1 & 30.53 & 23.37 & 46.08 \\
\hline A2 & 26.92 & 36.86 & 36.20 \\
\hline A3 & 32.96 & 32.96 & 34.07 \\
\hline A4 & 31.25 & 43.96 & 24.78 \\
\hline A5 & 36.18 & 39.59 & 24.22 \\
\hline
\end{tabular}

Figure S5. Measured oxidation of synthetic peptide oxidation isomers after being prepared by solid phase C18 extraction. (A) Extracted product ion chromatogram of c2 product ion from oxidized peptide precursor. Black trace shows selected ion chromatogram of oxidized isomer peptide. Red trace shows the unoxidized c2 ion, specific for the two isomers containing oxygen on $\mathrm{F}$ or $\mathrm{A}$, while the green trace shows the oxidized $\mathrm{c} 2$ ion, specific for oxidation of $\mathrm{P}$. Three traces are overlapping, indicating sample preparation using $\mathrm{C} 18$ solid phase extraction does not affect the co-elution of isomeric peptides. Markers on the peak indicate ETD spectra used for quantification. (B) Quantification of each oxidation isomer at each of five different elution times, using ETD product ion abundances. No systematic error is apparent, indicating solid phase $\mathrm{C} 18$ extractions using ZipTip does not cause inaccurate oxidation measurements. 


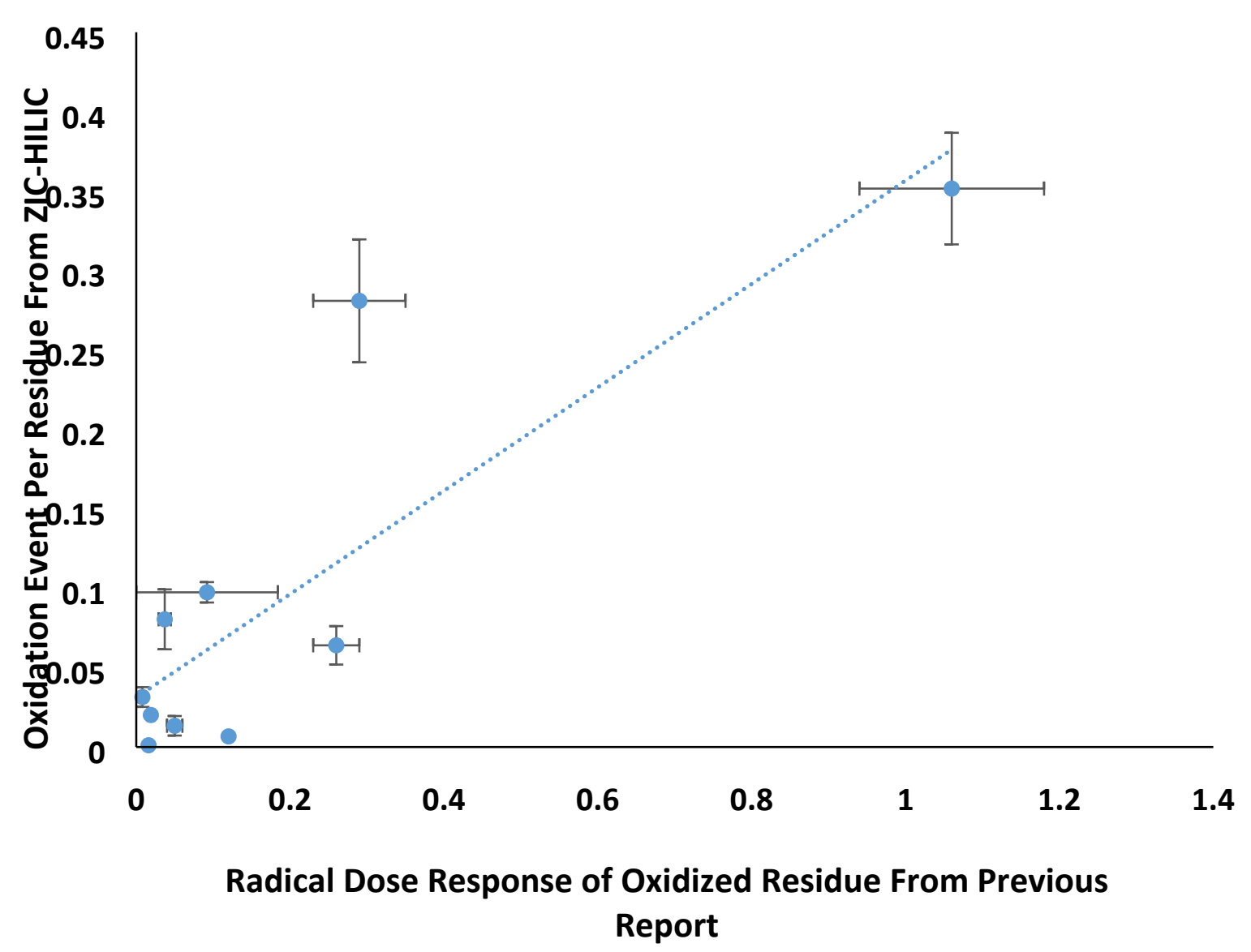

Figure S6. Comparison of oxidation event per amino acid via ZIC-HILIC with radical dose response of them via previous method ${ }^{1}$. 


\section{References:}

(1) Xie, B.; Sood, A.; Woods, R. J.; Sharp, J. S. Sci Rep 2017, 7, 4552. 